\title{
Comparison of power consumption of mobile WiMAX, HSPA and LTE access networks
}

\author{
Margot Deruyck, Willem Vereecken, Emmeric Tanghe, Wout Joseph, Mario Pickavet, Luc Martens, and \\ Piet Demeester
}

\begin{abstract}
Nowadays, wireless access networks are a large contributor to the $\mathrm{CO}_{2}$ emissions of ICT. Today, ICT is responsible for $4 \%$ of the annual energy consumption and this number is expected to grow drastically in the coming years. The power consumption of these wireless access networks will thus become an important issue in the coming years. In this paper, the power consumption of wireless base stations for mobile WiMAX, HSPA and LTE is modelled and compared for a future scenario.

For our research, we assume a suburban area and a physical bit rate of $10 \mathrm{Mbps}$. We compare the wireless technologies for a SISO and three MIMO systems. For each case, we give a ranking of the wireless technologies as a function of their power consumption, range and energy efficiency. Based on these results, we cover a specified area with each technology and determine which technology is the best solution for the specified area. We also compare the power consumption of the wireless access networks with the power consumption of the wired access networks.
\end{abstract} tion

Index Terms-base station, coverage, MIMO, power consump-

\section{INTRODUCTION}

$\mathbf{R}$ ECENT studies have shown that the power consumption of ICT is approximately $4 \%$ of the annual energy production [1]. More importantly, this number is expected to grow drastically in the coming years. Currently the transmitted data volume in communication networks doubles every five years. Moreover, the WWRF (Wireless World Research Forum) [2] has a vision of 7 trillion wireless devices serving 7 billion users by 2017. Furthermore, the radio access networks are large contributors to the $\mathrm{CO}_{2}$ emissions of ICT [1], [3], [4]. This indicates that the power consumption of wireless access networks, and more in particulary the power consumption of the base stations, is going to become an important issue in the coming years. Nowadays, the base stations are responsible for roughly two-thirds of the total $\mathrm{CO}_{2}$ emissions of the wireless access networks. [4] states that the daily energy consumption per customer is $0.83 \mathrm{Wh}$ for a terminal and $120 \mathrm{Wh}$ for the mobile network which is a consumption ratio of terminal versus network of about 1:150. The energy consumption of the terminals is thus negligible with respect to the energy consumption of the networks. Therefore, it is clear that one should focus on the base stations in the wireless access networks in order to reduce the energy consumption as the terminals are already optimized in terms of energy consumption because they work on batteries.

The purpose of this research is to model the power consumption of base stations of various wireless technologies.

All authors are with Ghent University / IBBT, Dept. of Information Technology, Gaston Crommenlaan 8 box 201, B-9050 Ghent, Belgium, email: margot.deruyck@intec.ugent.be
This power consumption is related to the coverage. Based on these characteristics we compare the different wireless technologies for a current and future scenario. Furthermore, we are able to compare the power consumption of the wireless access networks with the power consumption of the wired (or fixed) access networks.

For the wireless access networks, we investigate the power consumption of outdoor base stations for three different wireless technologies: mobile WiMAX (Worldwide Interoperability for Microwave Access), HSPA (High Speed Packet Access), and LTE (Long Term Evolution). For the wired access networks, the following technologies are considered: ADSL2 (Asymmetric Digital Subscriber Loop 2), VDSL2 (Very high speed Digital Subscriber Line 2), PtP fibre (1 Gbps) and GPON (Gigabit-capable Passive Optical Network).

The outline of the paper is as follows: in section II the considered technical scenarios are discussed and a theoretical power consumption model for wireless access networks is proposed. Section III provides the power efficiency versus the coverage of the considered wireless technologies using the model of Section II. These results are used in Section IV to determine the total power consumption in a suburban area for different wireless and wired technologies. In Section V conclusions are presented.

\section{METHOD}

\section{A. Scenarios}

In this investigation, we consider an indoor residential configuration in a suburban environment with a WNIC (Wireless Network Interface Card) for a laptop for the three technologies. Table I summarizes the configuration parameters for all technologies of Section I. We also define two technical scenarios for the outdoor base stations: a basic reference scenario and a future scenario. In the reference scenario, one receiving $(\mathrm{Rx})$ and one transmitting (Tx) antenna is considered i.e., a SISO system. In the reference scenario, both the base station and the receiver have multiple antennas i.e., a MIMO system. We consider a 2x1 MIMO system, a 2x2 MIMO system and a 4x4 MIMO system.

\section{B. Global}

In general a communication network consists of three different components: the home network also referred to as the CPE (Customer Premises Equipment), the access network and the core network. CPE is defined as any terminal equipment which resides at the customer's site, e.g. a WNIC is considered to 


\begin{tabular}{|l|c|c|}
\hline Parameter & Value & Unit \\
\hline Area type & Suburban & - \\
\hline$n_{\text {sector }}$ & 3 & - \\
\hline Height of base station & 30 & $\mathrm{~m}$ \\
\hline Height of mobile station & 1.5 & $\mathrm{~m}$ \\
\hline Coverage requirement & $90 \%$ & - \\
\hline Shadowing margin & 13.2 & $\mathrm{~dB}$ \\
\hline
\end{tabular}

TABLE I

CONFIGURATION TABLE.

be CPE for the wireless technologies. For the fixed technologies a home gateway is used at the customer premises. The $\mathrm{CPE}$ is connected with the core network through the access network. The access network is that part of a communication network which connects subscribers to their immediate service provider.

To compare the different technologies we define the total power consumption $P_{\text {tot }}^{u}$ per user (in Watt):

$$
P_{\text {tot }}^{u}=P_{\text {home }}^{u}+P_{\text {access }}^{u}+P_{\text {core }}^{u}
$$

with $P_{\text {home }}^{u}$ the power consumption of the CPE (Customer Premises Equipment) (in Watt), $P_{a c c e s s}^{u}$ the power consumption of the access network (in Watt) and $P_{\text {core }}^{u}$ the power consumption in the core network (in Watt). The wireless access network usually consists of base stations. The DSLAM (Digital Subscriber Line Access Multiplexer) and OLT (Optical Line Termination) are part of the access network for respectively the ADSL and VDSL technologies and the PtP optical networks and PON networks i.e., the fixed technologies. The core network is the central part of a telecommunication network that provides various services to customers who are connected by the access networks. The purpose of the core network is to interconnect several network sites or subnetworks. The main functionality of a core network is performed by routers.

\section{Theoretical model for wireless access}

In this section the model for determination of the power consumption $P_{a c c e s s}^{u}$ for wireless technologies is presented. The power consumption of a base station is evaluated. Based on this evaluation, we relate the power consumption of the base station to the wireless coverage range.

1) Power consumption of a base station: A base station is here defined as the equipment needed to communicate with the mobile stations and with the backhaul network. A base station typically consists of several power consuming components. Fig. 1 gives an overview of these components. Some equipment occurs per sector (then $n_{\text {sector }}$ times for all sectors) such as digital signal processing (responsible for system processing and coding), power amplifier, transceiver (responsible for receiving and sending of signals to the mobile stations), signal generator and the AC-DC converter. Furthermore, a base station contains equipment that is common for all the sectors such as the air conditioning and the microwave link (responsible for communication with the backhaul network). In Fig. 1, the equipment of the base station and the different notations for the power consumption $P_{e l}$ of the different parts are indicated.

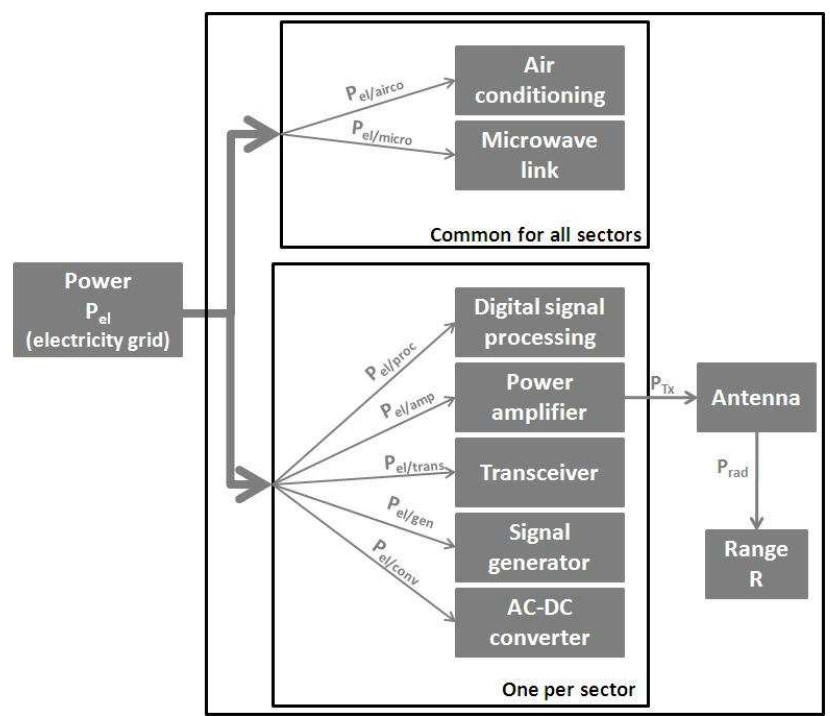

Fig. 1. Block diagram of the base station equipment

The power consumption of each part of the base station is a constant value (in Watt), except for the power amplifier. The power consumption of the power amplifier depends on the required input power $P_{T x}$ of the antenna. The power consumption $P_{\text {el/amp }}$ of the power amplifier (in Watt) is determined as follows [10]:

$$
P_{e l / a m p}=\frac{P_{T x}}{\eta}
$$

with $P_{T x}$ the input power of the antenna (in Watt) and $\eta$ the efficiency of the power amplifier which is the ratio of RF power $P_{\text {out } / a m p}$ (in Watt) to the electrical input power $P_{\text {el } / a m p}$ of the power amplifier (in Watt) [11].

Once we know the power consumption of the different components of the base station, we can calculate the power consumption $P_{e l}$ of the entire base station (in Watt):

$$
\begin{aligned}
P_{e l}= & n_{\text {sector }} \cdot\left(n_{T x} \cdot P_{e l / a m p}+P_{e l / \text { trans }}+P_{e l / p r o c}\right. \\
& \left.+P_{e l / c o n v}+P_{e l / g e n}\right)+P_{e l / \text { micro }}+P_{e l / \text { airco }}(3)
\end{aligned}
$$

with $n_{\text {sector }}$ the number of sectors in the cell, $P_{e l / a m p}$, $P_{\text {el/trans }}, P_{\text {el/proc }}, P_{\text {el/conv }}, P_{\text {el/gen }}, P_{\text {el/micro }}$ and $P_{\text {el/airco }}$ are the power consumptions of the power amplifier, the transceiver, the digital signal processing, the AC-DC converter, the generator, the microwave link and the air conditioning, respectively. Furthermore, $n_{T x}$ is the number of transmitting antennas per sector. Table II summarises the power consumption of the different components of a base station for the considered technologies. These values are retrieved from data sheets of various manufacturers of network equipment.

2) Calculation of the range $R$ : In this section, we want to relate the power consumption $P_{e l}$ of the base station to the wireless range $R$. For this, we have to set up a link budget. A link budget takes all of the gains and losses of the transmitter through the medium to the receiver into account. Firstly, we need to calculate the maximum path loss $P L_{\max }$ (in $\mathrm{dB}$ ) to which a transmitted signal can be subjected while still being detectable at the receiver. The path loss is the 


\begin{tabular}{|l|l|c|c|c|}
\hline Equipment & & $\begin{array}{c}\text { Mobile } \\
\text { WiMAX }\end{array}$ & HSPA & LTE \\
\hline $\begin{array}{l}\text { Digital signal } \\
\text { processing }\end{array}$ & $P_{\text {el } / \text { proc }}$ & $100 \mathrm{~W}$ & $100 \mathrm{~W}$ & $100 \mathrm{~W}$ \\
\hline Power & $P_{\text {el/amp }}$ & $100 \mathrm{~W}$ & $300 \mathrm{~W}$ & $350 \mathrm{~W}$ \\
amplifier & $\eta$ & $10 \%$ & $6.67 \%$ & $6.3 \%$ \\
SISO (1x1) & $R F_{\text {out }}$ & $40 \mathrm{dBm}$ & $43 \mathrm{dBm}$ & $43 \mathrm{dBm}$ \\
\hline Power & $P_{\text {el/amp }}$ & $10.4 \mathrm{~W}$ & $10.4 \mathrm{~W}$ & $10.4 \mathrm{~W}$ \\
amplifier & $\eta$ & $11.54 \%$ & $11.54 \%$ & $11.54 \%$ \\
MIMO & $R F_{\text {out }}$ & $30 \mathrm{dBm}$ & $30 \mathrm{dBm}$ & $30 \mathrm{dBm}$ \\
\hline Transceiver & $P_{\text {el/trans }}$ & $100 \mathrm{~W}$ & $100 \mathrm{~W}$ & $100 \mathrm{~W}$ \\
\hline Signal generator & $P_{\text {el/gen }}$ & $384 \mathrm{~W}$ & $384 \mathrm{~W}$ & $384 \mathrm{~W}$ \\
\hline AC-DC converter & $P_{\text {el/conv }}$ & $100 \mathrm{~W}$ & $100 \mathrm{~W}$ & $100 \mathrm{~W}$ \\
\hline Air conditioning & $P_{\text {el/airco }}$ & $690 \mathrm{~W}$ & $690 \mathrm{~W}$ & $690 \mathrm{~W}$ \\
\hline Microwave link & $P_{\text {el/micro }}$ & $80 \mathrm{~W}$ & $80 \mathrm{~W}$ & $80 \mathrm{~W}$ \\
\hline
\end{tabular}

TABLE II

POWER CONSUMPTION OF THE DIFFERENT PARTS OF THE WIRELESS BASE STATIONS.

ratio of the radiated power to the received power of the signal [12]. To determine the maximum path loss $P L_{\max }$ we need to take the parameters of Table III into account. Table III gives an overview of all the gains and losses that occur. These parameters are retrieved from the specifications and/or are typical values proposed by the operators self in order to make a fair comparison between the considered technologies. Furthermore, it is important to remark, that $P L_{\max }$ is dependent of the input power $P_{T x}$ of the antenna and thus dependent of the output power of the power amplifier which is $\eta \cdot P_{e l / a m p}$.

\begin{tabular}{|c|c|c|c|}
\hline Parameter & $\begin{array}{c}\text { Mobile } \\
\text { WiMAX }\end{array}$ & HSPA & LTE \\
\hline Frequency $[\mathrm{MHz}]$ & 2500 & 2100 & 2600 \\
\hline $\begin{array}{l}\text { Maximum input power } \\
\text { of base station }[\mathrm{dBm}]\end{array}$ & 35 & 24.7 & 43 \\
\hline Antenna gain of base station [dBi] & 16 & 17.4 & 18 \\
\hline Antenna gain of mobile station [dBi] & 2 & 0 & 0 \\
\hline Number of MIMO Tx antennas & \multicolumn{3}{|c|}{$1,2,4$} \\
\hline Number of MIMO Rx antennas & \multicolumn{3}{|c|}{$1,2,4$} \\
\hline MIMO gain $[\mathrm{dB}]$ & \multicolumn{3}{|c|}{$1 \times 1: 0,2 \times 1: 3,2 \times 2: 6,4 \times 4: 12$} \\
\hline $\begin{array}{l}\text { Cyclic combining gain } \\
\text { of base station [dB] }\end{array}$ & \multicolumn{3}{|c|}{3} \\
\hline Soft handover gain $[\mathrm{dB}]$ & 0 & 1.5 & 0 \\
\hline Feeder loss of base station $[\mathrm{dB}]$ & 0.5 & 0 & 2 \\
\hline Feeder loss of mobile station $[\mathrm{dB}]$ & \multicolumn{3}{|c|}{0} \\
\hline Fade margin $[\mathrm{dB}]$ & \multicolumn{3}{|c|}{10} \\
\hline Cell interference margin $[\mathrm{dB}]$ & \multicolumn{3}{|c|}{2} \\
\hline User speed $[\mathrm{km} / \mathrm{h}]$ & \multicolumn{3}{|c|}{0} \\
\hline Bandwidth [MHz] & 5 & 5 & 3 \\
\hline Receiver SNR [dB] & $15^{1}$ & $15.6^{2}$ & $29.4^{3}$ \\
\hline Number of used subcarriers & 360 & 1 & 151 \\
\hline Number of total subcarriers & 512 & 1 & 256 \\
\hline Noise figure of mobile station $[\mathrm{dB}]$ & 7 & 9 & 8 \\
\hline $\begin{array}{l}\text { Implementation loss } \\
\text { of mobile station }[\mathrm{dB}]\end{array}$ & 2 & 0 & 0 \\
\hline Duplexing & \multicolumn{3}{|c|}{ TDD } \\
\hline Building penetration loss $[\mathrm{dB}][20]$ & \multicolumn{3}{|c|}{8.1} \\
\hline
\end{tabular}

(1) 3/4 16-QAM, (2) 3/4 64-QAM, (3) 2/3 64-QAM

TABLE III

LINK BUDGET TABLE FOR THE WIRELESS TECHNOLOGIES.

Once we know the maximum path loss $P L_{\max }$, we can determine the maximum range $R$ (in metres) we can reach with the base station of a certain technology [10]:

$$
R=g^{-1}\left(P L_{\max }-S M \mid f, h_{B S}, h_{M S}\right)
$$

with $P L_{\max }$ the maximum path loss (in $\mathrm{dB}$ ), $S M$ the shadowing margin (in $\mathrm{dB}$ ), $f$ the frequency (in $\mathrm{Hz}$ ), $h_{B S}$ the height of the base station (in metres) and $h_{M S}$ the height of the mobile station (in metres). The shadowing margin depends on the standard deviation of the path loss model, the coverage percentage and the outdoor standard deviation. Here, we consider a coverage percentage of $90 \%$. The values for the other parameters can be found in Table I. The function $g($. depends on the used path loss model e.g., the HATA model and the Erceg model [13], [14]. In this paper, we use the Erceg $\mathrm{C}$ model. The quantity before the "|" in (4) is a variable and varies over a continuous interval, while the quantities after the "|" in (4) are parameters which take only one discrete known value.

\section{NUMERICAL ESTIMATIONS}

\section{A. Comparison of the wireless technologies}

In this section, we compare the following wireless technologies: mobile WiMAX, HSPA and LTE. We compare these technologies at a certain bit rate to make a fair comparison. Here, we define a bit rate of 10 Mbps. The parameters given in Tables I, I and III are used. For mobile WiMAX we used the 3/4 16-QAM constellation.

Fig. 2 shows the power $P_{e l}$ needed from the electricity grid (in Watt) as a function of the range $R$ (in metres) for the three different technologies. Table IV lists the values for $P_{e l}$, $R$ and $P C_{o p p}$ for the different technologies. $P C_{o p p}$ presents the power consumption per covered area (in $\mathrm{W} / \mathrm{m}^{2}$ ) [10]:

$$
P C_{\text {opp }}=\frac{P_{e l}}{\pi \cdot R^{2}}
$$

The lower $P C_{\text {opp }}$, the more energy-efficient the technology is.

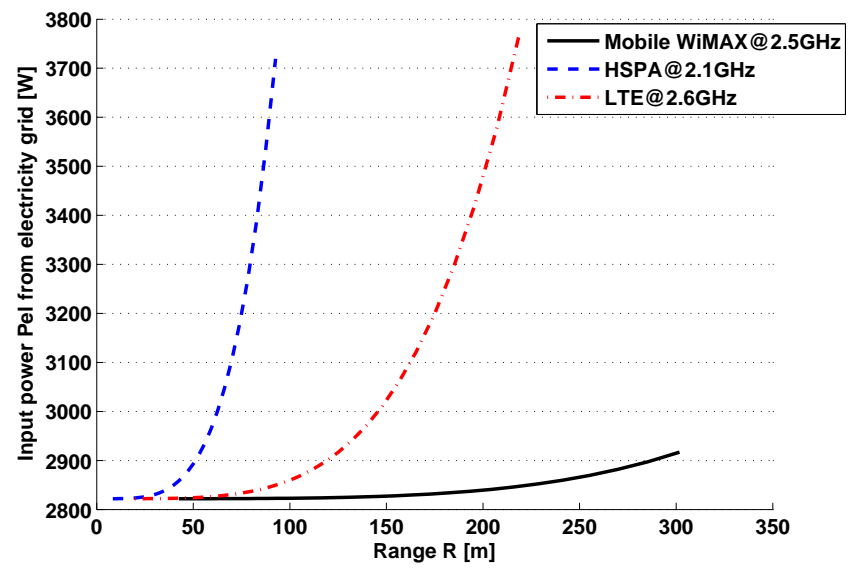

Fig. 2. Comparison of the technologies for a bit rate of approximately $10 \mathrm{Mbps}$

Fig. 2 and Table IV show that mobile WiMAX has the lowest power consumption, $2916.9 \mathrm{~W}$, and the highest range, $301.7 \mathrm{~m}$, resulting in the lowest value for $P C_{o p p}$ i.e., 


\begin{tabular}{|l|c|c|c|}
\hline & $\begin{array}{c}\text { Mobile } \\
\text { WiMAX }\end{array}$ & HSPA & LTE \\
\hline$P_{e l}[\mathrm{~W}]$ & 2916.9 & 3719.4 & 3772.1 \\
\hline$R[\mathrm{~m}]$ & 301.7 & 92.6 & 218.9 \\
\hline Bit rate $[\mathrm{Mbps}]$ & 11.5 & 11.3 & 10.20 \\
\hline$P C_{o p p}\left[\mathrm{~mW} / \mathrm{m}^{2}\right]$ & 10.2 & 138.07 & 25.06 \\
\hline
\end{tabular}

TABLE IV

COMPARISON OF THE WIRELESS TECHNOLOGIES FOR A BIT RATE OF APPROXIMATELY 10 MBPS

$10.2 \mathrm{~mW} / \mathrm{m}^{2}$ which makes mobile WiMAX the most energyefficient. HSPA has a power consumption $(3719.4 \mathrm{~W})$ that is $27.5 \%$ higher than the power consumption of mobile WiMAX, caused by the low efficiency $(6.67 \%)$ and the higher power consumption $(300 \mathrm{~W})$ of the power amplifier. Based on equation (2), one can see that a power amplifier with a higher efficiency consumes less power for the same $P_{T x}$. For this power consumption, HSPA has a range of only $92.6 \mathrm{~m}$. This range is $69.3 \%$ lower than for mobile WiMAX because the input power of the HSPA base station $(24.7 \mathrm{dBm})$ is lower than for the WiMAX base station $(35 \mathrm{dBm})$. The higher the input power of the base station is, the higher the reached range will be. Furthermore, mobile WiMAX has an antenna gain of $2 \mathrm{dBi}$ for the mobile station, while HSPA has no antenna gain at all. The high power consumption and the low range obtained with HSPA leads to a high value of $P C_{o p p}, 138.07 \mathrm{~mW} / \mathrm{m}^{2}$, which makes HSPA the least energy-efficient technology for this scenario. The power consumption of LTE (3772.1 W) is the highest of all technologies and is $29.3 \%$ higher than for mobile WiMAX. This high power consumption is again caused by the low efficiency $(6.3 \%)$ and the high power consumption $(350 \mathrm{~W})$ of the power amplifier. The input power of the LTE base station $(43 \mathrm{dBm})$ is also higher than the input power for the WiMAX base station $(35 \mathrm{dBm})$. Equation (2) shows that there is a direct connection between the input power and the power consumption of the base station. The higher the input power of the base station, the higher the power consumption of the base station. However, LTE reaches a range (218.9 m) which is $27.4 \%$ lower than the range obtained with mobile WiMAX. This range is lower because LTE works at a higher frequency $(2.6 \mathrm{GHz})$ than mobile WiMAX $(2.5 \mathrm{GHz})$ and because the required receiver SNR of LTE $(29.4 \mathrm{~dB})$ is very high compared to mobile WiMAX (15 dB) as shown in Table III.

For this scenario, we conclude that mobile WiMAX has the highest range and the lowest power consumption and is thus the most energy-efficient of the considered technologies. Furthermore, Table IV shows that mobile WiMAX has also the highest bit rate, $11.5 \mathrm{Mbps}$, for this scenario. Here, mobile WiMAX is definitely the best solution.

\section{B. Influence of $M I M O$}

In this section, we investigate the influence of MIMO on the power consumption and the range and compare the results with those of the $1 \times 1$ SISO system. We consider three MIMO systems: 2x1 MIMO (2 Tx and $1 \mathrm{Rx}$ antenna), 2x2 MIMO (2 Tx and $2 \mathrm{Rx}$ antennas) and 4x4 MIMO (4 Tx and $4 \mathrm{Rx}$ antennas). For the $2 \times 1$ MIMO system we consider a bit rate of approximately $10 \mathrm{Mbps}$, for the 2x2 MIMO system a bit rate of approximately $20 \mathrm{Mbps}$ and for the 4x4 MIMO system a bit rate of approximately $40 \mathrm{Mbps}$. The settings can be found in Tables I, II and III.

Table $\mathrm{V}$ summarizes the results for the $2 \times 1,2 \times 2$ and $4 \times 4$ MIMO system. Table $\mathrm{V}$ shows for mobile WiMAX the highest ranges $(422.3 \mathrm{~m}, 499.7 \mathrm{~m}$ and $699.8 \mathrm{~m}$ for a $2 \times 1,2 \times 2$ and $4 \times 4$ MIMO system, respectively) and the lowest power consumptions (2986.4 W for 2x1 and 2x2 MIMO system and $3150.8 \mathrm{~W}$ for a $4 \times 4$ MIMO system), resulting in low values for $P C_{o p p}\left(5.33 \mathrm{~mW} / \mathrm{m}^{2}, 3.81 \mathrm{~mW} / \mathrm{m}^{2}\right.$ and $2.05 \mathrm{~mW} / \mathrm{m}^{2}$ for a $2 \times 1,2 \times 2$ and $4 \times 4$ MIMO system, respectively). Mobile WiMAX is thus the most energy-efficient technology and has the highest bit rates of all the considered technologies (Table V). The least energy-efficient technology is HSPA. HSPA has the same power consumption as LTE but ranges that are much lower than for LTE leading to higher values for $P C_{\text {opp }}$ (Table V).

\begin{tabular}{|c|c|c|c|}
\hline 2x1 MIMO & $\begin{array}{c}\text { Mobile } \\
\text { WiMAX }\end{array}$ & HSPA & LTE \\
\hline$P_{e l}[\mathrm{~W}]$ & 2986.4 & 3859.4 & 3859.4 \\
\hline$R[\mathrm{~m}]$ & 422.3 & 129.6 & 306.4 \\
\hline Bit rate $[\mathrm{Mbps}]$ & 11.5 & 11.3 & 10.20 \\
\hline$P C_{o p p}\left[\mathrm{~mW} / \mathrm{m}^{2}\right]$ & 5.33 & 73.14 & 13.09 \\
\hline 2x2 MIMO & $\begin{array}{c}\text { Mobile } \\
\text { WiMAX }\end{array}$ & $\overline{\text { HSPA }}$ & $\overline{\text { LTE }}$ \\
\hline$P_{e l}[\mathrm{~W}]$ & 2986.4 & 3859.4 & 3859.4 \\
\hline$R[\mathrm{~m}]$ & 499.7 & 153.3 & 362.6 \\
\hline Bit rate $[\mathrm{Mbps}]$ & 23 & 22.6 & 20.40 \\
\hline$P C_{o p p}\left[\mathrm{~mW} / \mathrm{m}^{2}\right]$ & 3.81 & 52.27 & 9.34 \\
\hline 4x4 MIMO & $\begin{array}{c}\text { Mobile } \\
\text { WiMAX }\end{array}$ & $\overline{\text { HSPA }}$ & $\overline{\overline{\text { LTE }}}$ \\
\hline$P_{e l}[\mathrm{~W}]$ & 3150.8 & 4896.8 & 4896.8 \\
\hline$R[\mathrm{~m}]$ & 699.8 & 214.7 & 507.8 \\
\hline Bit rate $[\mathrm{Mbps}]$ & 46 & 45.2 & 40.8 \\
\hline$P C_{o p p}\left[\mathrm{~mW} / \mathrm{m}^{2}\right]$ & 2.05 & 33.81 & 6.05 \\
\hline
\end{tabular}

TABLE V

COMPARISON OF THE WIRELESS TECHNOLOGIES FOR 2X1, 2X2 AND 4X4 MIMO SYSTEM

In general, one can state that the energy efficiency increases when more receiving and transmitting antennas are used. The range increases with $40 \%, 66 \%$ and $132 \%$ for respectively a $2 \times 1,2 \times 2$ and $4 \times 4$ MIMO system compared to a $1 \times 1$ SISO system, while the power consumption increases with only 2 to $4 \%$ for a $2 \times 1$ and $2 \times 2$ MIMO system compared to a $1 \times 1$ SISO system. From equation (3) one can see that only the Tx antennas are taken into account. For a 4x4 MIMO system the power consumption increases with only $8 \%$ for mobile WiMAX and 30 to $32 \%$ for HSPA and LTE compared to the $1 x 1$ SISO system. The highest energy efficiency is reached with a 4x4 MIMO system.

\section{Coverage of an area}

In this section, we investigate how much electrical power we need to cover a pre-defined area with the base stations of each technology. Important to remark is that we only use one technology at a time. The surface $S$ of the suburban area 
we want to cover is $100 \mathrm{~km}^{2}$. We define three types of base stations according to the used technology. Table II gives an overview of the most important characteristics of the base stations. The other settings can be found in Tables I and III.

We calculate how much base stations \#BS we need as follows [10]:

$$
\# B S=\left\lceil\frac{S}{\pi \cdot R^{2}}\right\rceil
$$

with $R$ the range of the base station (in metres) and $[$.$] the ceil$ function. Table VI lists the results for a $4 \times 4$ MIMO system. $P_{\text {tot }}$ (in $\mathrm{kW}$ ) gives an estimation of the power consumption of all the required base stations.

\begin{tabular}{|l|c|c|}
\hline & $\# B S$ & $P_{\text {tot }}[\mathrm{kW}]$ \\
\hline Mobile WiMAX & 65 & 204.8 \\
\hline HSPA & 205 & 1003.8 \\
\hline LTE & 124 & 607.2 \\
\hline
\end{tabular}

TABLE VI

COMPARISON OF THE WIRELESS TECHNOLOGIES FOR THE COVERAGE OF AN AREA WITH A 4X4 MIMO SYSTEM

From Table VI, we conclude that mobile WiMAX is the best solution. Mobile WiMAX needs only 65 base stations and has a total power consumption of $204.8 \mathrm{~kW}$. This is selfevident because in Section III-B we saw that the WiMAX base station has the highest range and the lowest power consumption. Furthermore, we conclude that HSPA is not a good solution to cover the area. HSPA needs the highest number of base stations and has thus a high total power consumption (Table VI).

\section{Comparative Evaluation}

We now compare the power consumption of the different wireless access technologies with the power consumption of the wireline access technologies. Therefore, we determine $P_{\text {tot }}^{u}$, defined in equation (1), for each technology. We assume a rollout in a suburban area of $100 \mathrm{~km}^{2}$ with 300 subscribers $/ \mathrm{km}^{2}$.

\section{A. Power consumption $P_{\text {home }}^{u}$ of the home networks}

For the customer premises equipment, power consumption values per user are found in [15] for each technology. These values are listed in Table VII. For the fixed line technologies, ADSL2 home equipment consumes between 3.8 and $5.0 \mathrm{~W}$, VDSL2 between 6.0 and 7.5 W, PtP optical between 5.6 and 7.1 W, and GPON home devices between 7.7 and $9.7 \mathrm{~W}$. For the wireless technologies, we consider mobile applications. The CPE for mobile applications is typically designed to have a low power consumption in order to allow long autonomy times. The CPE can come in many forms but in this work we consider a USB modem. Based on the specifications of several commercial devices, the power consumption of USB modems is estimated at $2.5 \mathrm{~W}$. In applications where the wireless technology is used to simply replace the fixed line technology (e.g. fixed WiMAX) the home equipment has higher power consumptions typically in the range between 5 and $10 \mathrm{~W}$. In this work we do not elaborate on this case but generally one can say that this application will consume more power than the mobile application. Note on the other hand, that for the home network we only consider the device which allows the customer to connect to the access network. PCs, televisions, settop-boxes, etc. have not been accounted for both the wireless and the wired case.

\section{B. Power consumption $P_{\text {access }}^{u}$ of the access networks}

For the wireless technologies, we define the power consumption per user $P_{\text {access }}^{u}$ (in Watt) as follows [10]:

$$
P_{\text {access }}^{u}=\frac{P C_{o p p}}{N}
$$

with $P C_{o p p}$ the power consumption per area (in $\mathrm{W} / \mathrm{km}^{2}$ ) and $N$ the number of subscribers per $\mathrm{km}^{2}$. Table VII shows the results for $P_{a c c e s s}^{u}$ obtained with equation (7) and the values for $P C_{o p p}$ retrieved from Table IV.

The power consumption for ADSL2 and VDSL2 access network devices is approximately 1.95 and $3.0 \mathrm{~W}$ per user, respectively [15]. Note that for VDSL2 networks, the maximum distance between the user and the DSLAM is about $300 \mathrm{~m}$. On the other hand, VDSL2 enables access rates of $100 \mathrm{Mbps}$. Note that VDSL2 offers higher bit rates than ADSL2, but at lower distances between the user and the DSLAM. At $26 \mathrm{Mbps}$ the range is about $1 \mathrm{~km}$ and whereas for bit rates up to $100 \mathrm{Mbps}$ the range is smaller than $300 \mathrm{~m}$. For PtP optical networks, the power consumption of access network devices is between 4.5 and 7.5 W per user at $1 \mathrm{Gbps}$ [15]. For GPON devices, for which we assume a distribution ratio of 64 users per port, the power consumption is 0.35 to $0.47 \mathrm{~W}$ per user ${ }^{1}$. Although the capacity of the optical fiber is shared over multiple users in GPON, the architecture allows for peak bit rates comparable to PtP due to the traffic aggregation on the shared medium. It is important to note that although optical networks have a much lower power consumption compared to the wireless access networks, they have a much higher cost rolling them out. In [16] an analysis was performed and it was shown that the cost of keeping an optical access network up and running is only $10 \%$ of the investment in a roll-out. This indicates that when making a fair comparison between the different technologies concerning power consumption and carbon footprint, life cycle assessment is required. This is however out of the scope for this paper.

\section{Power consumption $P_{\text {core }}^{u}$ of the core networks}

For the core networks, we assume the same network for all the considered wireless and wired technologies i.e., a DSL network. In [17], it is estimated that $P_{\text {core }}^{u}=11 \% \cdot P_{\text {access }}^{u}$. We will consider this estimation for the power consumption values of the DSL core networks. We found a $P_{\text {access }}^{u}$ between $1.3-2.0 \mathrm{~W}$ for the DSL access networks, which results in a $P_{\text {core }}^{u}$ of approximately $0.14-0.22 \mathrm{~W}$ for the core network [15]. Note that these numbers do not include the power consumption of cooling which we did consider when modelling the wireless access networks. In order to incorporate

\footnotetext{
${ }^{1}$ Point to point technologies allow ranges up to $60 \mathrm{~km}$. GPON technologies allow ranges between $10 \mathrm{~km}$ (split ratio 64) and $20 \mathrm{~km}$ (split ratio 32)
} 


\begin{tabular}{|l|ccc|c|}
\hline & $\begin{array}{c}P_{\text {home }}^{u} \\
{[\mathrm{~W}]}\end{array}$ & $\begin{array}{c}P_{\text {access }}^{u} \\
{[\mathrm{~W}]}\end{array}$ & $\begin{array}{c}P_{\text {core }}^{u} \\
{[\mathrm{~W}]}\end{array}$ & $\begin{array}{c}P_{\text {tot }}^{u} \\
{[\mathrm{~W}]}\end{array}$ \\
\hline Mobile WiMAX & 2.5 & 34.0 & $0.28-0.44$ & $36.78-36.94$ \\
\hline HSPA & 2.5 & 462.3 & $0.28-0.44$ & $465.08-465.24$ \\
\hline LTE & 2.5 & 83.5 & $0.28-0.44$ & $86.28-86.44$ \\
\hline ADSL2 & $3.8-5.0$ & 1.95 & $0.28-0.44$ & $6.03-7.39$ \\
\hline VDSL2 & $6.0-7.5$ & 3.0 & $0.28-0.44$ & $9.28-10.94$ \\
\hline PtP fibre (1 Gbps) & $5.6-7.1$ & $4.5-7.5$ & $0.28-0.44$ & $10.38-15.04$ \\
\hline GPON & $7.7-9.7$ & $0.35-0.47$ & $0.28-0.44$ & $8.33-10.61$ \\
\hline
\end{tabular}

TABLE VII

COMPARISON OF THE POWER CONSUMPTION PER USER FOR THE DIFFERENT TECHNOLOGIES

this power consumption we will multiply the values with a Power Usage Effectiveness (PUE) which expresses the overall power consumption divided by the ICT device power consumption [18]. For the core networks a PUE of 2 is assumed which is typical for data centers.

\section{Comparison of the different technologies}

Table VII summarizes the power consumption per user for the considered technologies. For the wireless technologies, one can see that mobile WiMAX is the best solution. For mobile WiMAX the lowest values for $P_{t o t}^{u}(36.78-36.94 \mathrm{~W})$ are obtained, which is evident because mobile WiMAX has the lowest value for $P_{\text {access }}^{u}(34.0 \mathrm{~W}) . P_{\text {home }}^{u}$ and $P_{\text {core }}^{u}$ are the same for all the wireless technologies because they can use the same CPE and we considered the same core network for the different technologies. Furthermore, we can conclude that HSPA performs worst of all the technologies because of the high power consumption of the access network.

For the wired technologies, Table VII shows that ADSL2 is the best solution. ADSL2 has a $P_{t o t}^{u}$ of 6.03-7.39 W which is the lowest value for $P_{\text {tot }}^{u}$ because both $P_{\text {home }}^{u}(3.8-5.0 \mathrm{~W})$ and $P_{\text {access }}^{u}(1.95 \mathrm{~W})$ are the lowest for ADSL2. If we compare ADSL2 with mobile WiMAX, we see that ADSL2 performs better. Although mobile WiMAX has the lowest $P_{\text {home }}^{u}, P_{\text {access }}^{u}$ is higher than ADSL2. The higher $P_{\text {access }}^{u}$ for mobile WiMAX is caused by the power consumption of the WiMAX base station.

Fig. 3 gives an overview of the contribution of each part of the network to the total power consumption. For the wireless technologies, it is clear that the access network contributes the most to the total power consumption. For wired technologies, in contrary, the home network is the largest contributor. We conclude that the wireless access networks are consuming significantly more power consumption than the wired access networks. This result is an obvious motive to reduce the power consumption of the base stations in order to make wireless and wired access networks competitive in terms of power consumption per user.

\section{CONCLUSiOnS}

In this paper, the power consumption for three different wireless technologies, namely mobile WiMAX, HSPA and LTE, is investigated. This power consumption is related to the coverage of their outdoor base stations. For the mobile stations, we considered an indoor residential scenario with a

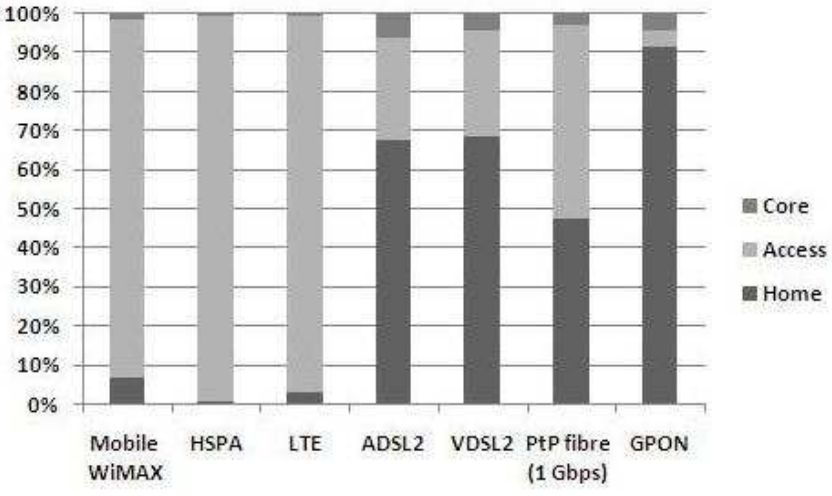

Fig. 3. Comparison of the power consumption per user for different technologies

WNIC for all the considered technologies. With a pre-defined bit rate of $10 \mathrm{Mbps}$, we found that mobile WiMAX is the most energy-efficient solution. LTE has a power consumption that is $29 \%$ higher and a range that is $27 \%$ lower than mobile WiMAX. HSPA is the least energy-efficient and has a range that is $69 \%$ lower than for mobile WiMAX while the power consumption is $28 \%$ higher.

When MIMO is introduced, we concluded that each technology becomes more energy-efficient. When we compare a $4 \times 4$ MIMO system with a $1 x 1$ SISO system, the range increases with $132 \%$, while the power consumption increases with only $8 \%$ for mobile WiMAX and 30 to $32 \%$ for HSPA and LTE. The $4 \times 4$ MIMO system is for each technology the most energy-efficient. Mobile WiMAX is the best solution for this future scenario.

Also for the coverage of a suburban area of $100 \mathrm{~km}^{2}$ mobile WiMAX is a good solution. It needs the lowest number of base stations (65) and has the lowest total power consumption $\left(P_{t o t}=204.8 \mathrm{~kW}\right)$ of all considered technologies.

The power consumption per user is also investigated in this paper. For the wireless access network, the best solution is again mobile WiMAX with a total power consumption per user $P_{t o t}^{u}$ of $37 \mathrm{~W}$. The best solution of all the considered wireless and wired technologies is ADSL2 which has a $P_{t o t}^{u}$ that is $81 \%$ lower than the $P_{t o t}^{u}$ of mobile WiMAX. Furthermore, we concluded that for the wireless technologies, the access network is the largest contributor to $P_{t o t}^{u}$. In order to make wireless and wired technologies competitive in terms of energy efficiency, this result shows that it is interesting to investigate how the power consumption of the base stations of the wireless 
technologies can be reduced.

\section{ACKNOWLEDGMENT}

W. Joseph is a Post-Doctoral Fellow of the FWO-V (Research Foundation Flanders).

\section{REFERENCES}

[1] M. Pickavet, W. Vereecken, S. Demeyer, P. Audenaert, B. Vermeulen, C. Develder, D. Colle, B. Dhoedt, and P. Demeester, "Worldwide Energy Needs for ICT: the Rise of Power-Aware Networking," in 2008 IEEE ANTS Conference, Bombay, India, December 2008.

[2] "World wireless research forum," www.wireless-world-research.org.

[3] Ericsson, "Sustainable energy use in mobile communications," White paper, August 2007.

[4] M. Etoh, T. Ohya, and Y. Nakayama, "Energy Consumption Issues on Mobile Network Systems," in International Symposium Issues on Mobile Network Systems, 2008.

[5] Air Interface for Fixed Broadband Wireless Access Systems, IEEE 802.16 Working Group on Broadband Wireless Access Standards, October 2004. [Online]. Available: www.ieee802.org/16

[6] 3rd Generation Partnership Project: Technical Specification Group Radio Access Network: Physical layer aspects of UTRA High Speed Downlink Packet Access (Release 4), TR 25.848 v4.0.0., 3GPP.

[7] LTE: Evolved Universal Terrestrial Radio Access (E-UTRA): User Equipment (UE) radio transmission and reception (TS 36.101 v9.1.0 Release 9 , 3GPP

[8] TeliaSonera, "TeliaSonera first in the world with 4G services," December 2009. [Online]. Available: www.teliasonera.com/press/pressreleases/item.page?prs.itemId=463244

[9] Asymmetric Digital Subscriber Loop 2, International Telecommunication Union - Telecommunications sector. [Online]. Available: http://www.itu.int/rec/T-REC-G.992.3/en

[10] M. Deruyck, W. Vereecken, E. Tanghe, W. Joseph, M. Pickavet, L. Martens, and P. Demeester, "Power consumption in Wireless Access Networks," in 2010 European Wireless Conference, 2010.

[11] F. H. Raab, P. Asbeck, S. Cripps, P. B. Kenington, Z. B. Popovic, N. Pothecary, J. F. Sevic, and N. O. Sokal, "RF and Microwave Power Amplifier and Transmitter Technologies - Part 1," High Frequency Electronics, pp. 22-36, May 2003.

[12] S. Saunders, Antennas and Propagation for Wireless Communication Systems. Wiley, 1999.

[13] M. Hata, "Empirical Formula for Propagation Loss in Land Mobile Radio Services," IEEE Transactions on Vehicular Technology, vol. 29, no. 3, pp. 317-325, August 1980.

[14] V. Erceg, L. Greenstein, S. Tjandra, S. Parkoff, A. Gupta, B. Kulic, A. Julius, and R. Bianchi, "An Emperically Based Path Loss Model for Wireless Channels in Suburban Environments," IEEE Journal on Selected Areas in Communications, vol. 29, no. 7, July 1999.

[15] European Commission, "Code of conduct on energy consumption of broadband equipment version 3," November 2008.

[16] K. Casier, S. Verbrugge, R. Meersman, D. Colle, M. Pickavet, and P. Demeester, "A clear and balanced view on fibre to the home deployment costs," Journal of The Institute of Telecommunications Professionals, vol. 2, pp. 27-31, December 2008.

[17] J. Baliga, R. Ayre, K. Hinton, W. Sorin, and R. Tucker, "Energy consumption in optical ip networks," Lightwave Technology, Journal of, vol. 27, no. 13, pp. 2391-2403, July1, 2009.

[18] The Green Grid, "Green grid metrics: Describing datacenter power efficiency," http://www.thegreengrid.org, February 2007.

[19] L. Hérault, "Green Wireless Communications eMobility GA1."

[20] D. Plets, W. Joseph, L. Verloock, L. Martens, H. Gauderis, and E. Deventer, "Extensive Penetration Loss Measurements and Models for Different Building Types for DVB-H in the UHF Band," IEEE Transactions on broadcasting, vol. 55, no. 2, pp. 213 - 222, June 2009. 